\title{
Preventing hypoglycaemia: what is the appropriate glucose alert value?
}

\author{
P. E. Cryer
}

Received: 16 October 2008 / Accepted: 21 October 2008 / Published online: 19 November 2008

(C) Springer-Verlag 2008

Keywords Glucose alert value · Glucose counter-regulation · Hypoglycaemia $\cdot$ Self-monitoring of plasma glucose

\section{Abbreviation \\ ADA American Diabetes Association}

Everyone is entitled to their own opinion, but not their own facts.

\section{Daniel Patrick Moynihan}

Contrary to the assertions of Swinnen et al. [1], Frier [2] and Amiel et al. [3], the American Diabetes Association (ADA) Workgroup on Hypoglycemia [4] defined hypoglycaemia in diabetes as 'all episodes of an abnormally low plasma glucose concentration that expose the individual to potential harm'. It is not possible to state a single plasma glucose concentration that defines hypoglycaemia because the glycaemic thresholds for responses to falling glucose levels, including those for symptoms, are dynamic. The ADA Workgroup recommended that people with diabetes (implicitly those with insulin secretagogue- or insulin-treated diabetes) should become concerned about the possibility of developing hypoglycaemia at a self-monitored plasma glucose concentration of $\leq 3.9 \mathrm{mmol} / \mathrm{l}(70 \mathrm{mg} / \mathrm{dl})$ [4]. Given

This invited For Debate article reflects the views of the author, not necessarily those of the American Diabetes Association (ADA) or the ADA Workgroup on Hypoglycemia.

\section{P. E. Cryer $(\bowtie)$}

Division of Endocrinology, Metabolism and Lipid Research,

Washington University School of Medicine,

Campus Box 8127, 660 South Euclid Avenue,

St Louis, MO 63110, USA

e-mail: pcryer@wustl.edu the limited accuracy of monitoring devices [5], this conservative lower limit for individuals with diabetes approximates the lower limit of the postabsorptive plasma glucose concentration range (approximately $3.9-6.1 \mathrm{mmol} / \mathrm{l}$ [70-110 mg/dl] [6]) and the glycaemic threshold for activation of glucose counter-regulatory systems (approximately $3.6-3.9 \mathrm{mmol} / \mathrm{l}[65-70 \mathrm{mg} / \mathrm{dl}]$ [6-9]), and is low enough to cause reduced glucose counter-regulatory responses to subsequent hypoglycaemia [10] in non-diabetic individuals. It is higher than the glucose levels required to produce symptoms in non-diabetic individuals (approximately $2.8-3.1 \mathrm{mmol} / 1$ [50-55 mg/dl] [6-9]) and substantially higher than those that do so in people with well-controlled diabetes [11], although individuals with poorly controlled diabetes sometimes have symptoms at higher glucose levels $[11,12]$. Thus, the recommended glucose alert level of $\leq 3.9 \mathrm{mmol} / \mathrm{l}(70 \mathrm{mg} / \mathrm{dl})$ is data-driven, generally gives the patient time to take action to prevent a clinical hypoglycaemic episode, and provides some margin for the limited accuracy of glucose monitoring devices at low plasma glucose concentrations [5]. The ADA Workgroup-recommended alert value does not, of course, mean that people with diabetes should always self-treat at an estimated plasma glucose concentration of $\leq 3.9 \mathrm{mmol} / \mathrm{l}(70 \mathrm{mg} / \mathrm{dl})$. Rather, it suggests that they should consider actions ranging from repeating the measurement in the short term, through behavioural changes such as avoiding exercise or driving, to carbohydrate ingestion and adjustments of the treatment regimen.

The data reported by Swinnen et al. [1] nicely document that a higher plasma glucose cut-off value increases the percentage of affected patients and increases the proportion of patients who are asymptomatic; but those are predictable findings. Their data also indicate that a higher cut-off value 
identifies a higher percentage of patients who suffer severe hypoglycaemia, i.e. it increases sensitivity, albeit at the expense of specificity. This is in line with the evidence of Cox et al. [13] that increasingly frequent lower selfmonitored glucose levels identify an increasing risk of imminent severe hypoglycaemia in people with diabetes.

Swinnen et al. [1], Frier [2] and Amiel et al. [3] opine that a lower plasma glucose concentration alert value would be preferable. Collectively, they raise four points. First, plasma glucose concentrations $\leq 3.9 \mathrm{mmol} / 1(70 \mathrm{mg} / \mathrm{dl})$ sometimes occur in non-diabetic individuals $[1,3]$. This is true, particularly in women and children, albeit generally during prolonged fasting. However, its relevance to people with diabetes, in whom lower glucose levels predict subsequent severe hypoglycaemia [13], is questionable. Second, use of a glucose cut-off value of $\leq 3.9 \mathrm{mmol} / 1(70 \mathrm{mg} / \mathrm{dl})$ would overestimate the frequency of clinically important hypoglycaemia $[1,3]$ or inflate the frequency of clinically meaningless biochemical hypoglycaemia [2]. This criticism is wide of the mark. The issue is not to estimate the frequency of clinically important hypoglycaemia. It is to prevent clinically important hypoglycaemia. A related point is that the guidance given by the Committee for Proprietary Medicinal Products of the European Agency for the Evaluation of Medicinal Products (EMEA/CPMP) [14] on the clinical investigation of medicinal products in the treatment of diabetes, cited by Amiel et al. [3], suggests that the selected glucose level needs to be lower than in clinical practice because a high level of specificity is needed to make claims. But, the issue under discussion is clinical practice, not claims. Furthermore, the guidance includes the erroneous statement that 'in type 2 diabetes, episodes of hypoglycaemia with severe CNS dysfunction are rare' [14]. In fact, most episodes of iatrogenic hypoglycaemia, including severe hypoglycaemia, occur in people with type 2 diabetes [15]. Third, the clinical significance of plasma glucose levels of 3.5$4.0 \mathrm{mmol} / 1(63-72 \mathrm{mg} / \mathrm{dl})$ is probably minor [1], and many clinicians would not consider these to represent significant hypoglycaemia [3]. This ignores the evidence that antecedent plasma glucose concentrations of $3.9 \mathrm{mmol} / \mathrm{l}(70 \mathrm{mg} / \mathrm{dl})$ reduce the glucose counter-regulatory (including sympathoadrenal) responses to subsequent hypoglycaemia [10], and these diminished responses are a key feature of the pathogenesis of iatrogenic hypoglycaemia in diabetes [15]. Fourth, strict avoidance of such levels is likely to have an adverse effect on average glycaemia [1]. This is entirely speculative.

Frier raises additional issues [2]. His points about the technical aspects of glucose measurements are true, but, in my view, clinically irrelevant given the limited accuracy of devices for self-monitoring blood glucose-generally calibrated to provide estimates of plasma glucose concentrations - at low glucose levels. For example, in one study of a monitor judged by the authors to provide a high degree of accuracy, at glucose levels $\leq 3.9 \mathrm{mmol} / 1(70 \mathrm{mg} / \mathrm{dl})$, monitor values were within $10 \%$ of the reference blood glucose concentration only $55 \%$ of the time and within $15 \%$ of the reference value only $70 \%$ of the time [5]. With respect to his criticisms of the hyperinsulinaemiceuglycaemic and -hypoglycaemic clamp techniques, intraindividual differences of approximately $0.2 \mathrm{mmol} / 1(4 \mathrm{mg} / \mathrm{dl})$ [16] hardly represent striking discrepancies; indeed, the authors concluded that the method gave reproducible results [16]. Notably, in his thorough analysis of the methods prior to 1993, Heine [17] specifically endorsed the method used to calculate the glycaemic thresholds for glucose counter-regulatory and symptomatic responses to hypoglycaemia in two of the three studies [7, 8] that generated the glycaemic thresholds mentioned earlier [6]. He also made the point that since 'real life' is often replete with uncontrollable confounding factors, its simulation should not be the prime consideration when performing scientific studies [17].

Swinnen et al. [1] advocate a plasma glucose concentration cut-off value lower than $3.9 \mathrm{mmol} / 1(70 \mathrm{mg} / \mathrm{dl})$, but do not suggest a specific alternative. With no data-driven rationale whatsoever, Frier [2] suggests a cut-off value of $3.5 \mathrm{mmol} / \mathrm{l}(63 \mathrm{mg} / \mathrm{dl})$, a difference of $0.4 \mathrm{mmol} / \mathrm{l}(7 \mathrm{mg} / \mathrm{dl})$ from the ADA Workgroup-recommended alert value. Amiel et al. [3] also suggest a value of $3.5 \mathrm{mmol} / 1(63 \mathrm{mg} / \mathrm{dl})$. Notably, however, they basically endorse the ADA Workgroup alert value, or an even higher value, in that they recommend a therapeutic plasma glucose concentration lower limit of $4.0-4.5 \mathrm{mmol} / 1(72-81 \mathrm{mg} / \mathrm{dl})$. Thus, it seems there is actually rather little disagreement on this ostensibly contentious issue.

Acknowledgements The author's original work cited was supported, in part, by US National Institutes of Health grants R37 DK27085, MO1 RR00036 (now UL1 RR24992) and P60 DK20579 and a fellowship award from the American Diabetes Association. J. Dedeke prepared this manuscript.

Duality of interest The author has served as a consultant for Merck, Marcadia Biotech, Novo Nordisk, Johnson \& Johnson, MannKind, Medtronic MiniMed, Takeda and TolerRx in recent years.

\section{References}

1. Swinnen SGHA, Mullins P, Miller M, Hoekstra JBL, Holleman F (2009) Changing the glucose cut-off values that define hypoglycaemia has a major effect on reported frequencies of hypoglycaemia. Diabetologia doi:10.1007/s00125-008-1147-0

2. Frier BM (2009) Defining hypoglycaemia: what level has clinical relevance? Diabetologia doi:10.1007/s00125-008-1209-3

3. Amiel SA, Dixon T, Mann R, Jameson K (2008) Hypoglycaemia in type 2 diabetes. Diabet Med 25:245-254 
4. American Diabetes Association Workgroup on Hypoglycemia (2005) Defining and reporting hypoglycemia in diabetes. Diabetes Care 28:1245-1249

5. The Diabetes Research in Children Network (DirecNet) Study Group (2003) A multicenter study of the accuracy of the One Touch Ultra home glucose meter in children with type 1 diabetes. Diabetes Technol Ther 5:933-941

6. Cryer PE (2001) The prevention and correction of hypoglycemia. In: Jefferson LS, Cherrington AD (eds) Handbook of physiology, Section 7, the endocrine system. Volume II, the endocrine pancreas and regulation of metabolism. Oxford University Press, New York, pp 1057-1092

7. Schwartz NS, Clutter WE, Shah SD, Cryer PE (1987) Glycemic thresholds for activation of glucose counterregulatory systems are higher than the threshold for symptoms. J Clin Invest 79:777-781

8. Mitrakou A, Ryan C, Veneman T et al (1991) Hierarchy of glycemic thresholds for counterregulatory hormone secretion, symptoms and cerebral dysfunction. Am J Physiol Endocrinol Metab 260:E67-E74

9. Fanelli C, Pampanelli S, Epifano L et al (1994) Relative roles of insulin and hypoglycaemia on induction of neuroendocrine responses to, symptoms of, and deterioration of cognitive function in hypoglycaemia in male and female humans. Diabetologia 37:797-807

10. Davis SN, Shavers C, Mosqueda-Garcia R, Costa F (1997) Effects of differing antecedent hypoglycemia on subsequent counterregulation in normal humans. Diabetes 46:1328-1335
11. Amiel SA, Sherwin RS, Simonson DC, Tamborlane WV (1988) Effect of intensive insulin therapy on glycemic thresholds for counterregulatory hormone release. Diabetes 37:901-907

12. Boyle PJ, Schwartz NS, Shah SD, Clutter WE, Cryer PE (1988) Plasma glucose concentrations at the onset of hypoglycemic symptoms in patients with poorly controlled diabetes and in nondiabetics. N Engl J Med 318:1487-1492

13. Cox DJ, Gonder-Frederick L, Ritterbrand L, Clarke W, Kovatchev BP (2007) Prediction of severe hypoglycemia. Diabetes Care 30:1370 1373

14. Committee for Proprietary Medicinal Products of the European Agency for the Evaluation of Medicinal Products (2008) Note for guidance on clinical investigation of medicinal products in the treatment of diabetes mellitus. Available from: http://www. emea.europa.eu/pdfs/human/ewp/108000en.pdf, accessed 29 May 2008

15. Cryer PE (2008) The barrier of hypoglycemia in diabetes. Diabetes. doi:10.2337/db08-1084

16. Vea H, Jorde R, Sager G, Vaaler S, Sundsfjord J (1992) Reproducibility of glycaemic thresholds for activation of counterregulatory hormones and hypoglycaemic symptoms in healthy subjects. Diabetologia 35:958-961

17. Heine RJ (1993) Methods of investigation of insulin-induced hypoglycaemia. In: Frier BM, Fisher BM (eds) Hypoglycaemic in diabetes: clinical and physiological aspects. Arnold, London, pp $165-175$ 